Asian Journal of Plant Sciences 4 (3): 255-260, 2005

ISSN 1682-3974

(C) 2005 Asian Network for Scientific Information

\title{
Effect of Duration of Light:Dark Cycles on in vitro Shoot Regeneration of Tomato
}

\author{
Poonam Bhatia and Nanjappa Ashwath \\ Primary Industries Research Centre, School of Biological and Environmental Sciences, \\ Central Queensland University, Rockhampton, QLD 4702, Australia
}

\begin{abstract}
Cotyledonary explants of the Red Coat cultivar were exposed to light: dark cycles in regeneration medium (MS basal $+15 \mu \mathrm{M}$ zeatin) for four weeks, with the view of elucidating the role of light in direct shoot regeneration. Light has not been found essential for shoot regeneration in tomato. However, maximum shoot regeneration response $(60 \%)$ could only occur in the explants exposed to $16 \mathrm{~h} \mathrm{light}$ and $8 \mathrm{~h}$ dark. The response declined at $2 \mathrm{~h}$ dark (47\%) or $24 \mathrm{~h}$ light (40\%). Comparable number of shoots was produced in the $16 \mathrm{~h}$ light (3.3) and $24 \mathrm{~h}$ dark (3.2) treatments, but in $24 \mathrm{~h} \mathrm{light} \mathrm{treatment} \mathrm{the} \mathrm{number} \mathrm{of} \mathrm{shoots} \mathrm{produced} \mathrm{per} \mathrm{explant} \mathrm{was} \mathrm{less}$ (2.7). Shoots with maximum height were observed in $24 \mathrm{~h}$ light $(6.3 \mathrm{~mm})$ followed by $16 \mathrm{~h}$ light $(4.5 \mathrm{~mm})$ and $24 \mathrm{~h}$ dark $(3.9 \mathrm{~mm})$. The shoots regenerated in the dark were not etiolated. Mimicking of light regulated processes by exogenous application of high concentration of cytokinin can be the possible reason for the nonetiolated behaviour of the dark regenerated shoots. Although light was not essential for shoot regeneration, appropriate light:dark cycles were required for proper chlorophyll development.
\end{abstract}

Key words: Explant, micropropagation, morphogenesis, multiplication

\section{INTRODUCTION}

The in vitro regeneration capability of tomato is genetically controlled ${ }^{[1,2]}$. Thus, tomato plants posses the blueprint which dictates the way they will respond to a regeneration medium. The regeneration response is also influenced by the ambient conditions, as some growth processes are enhanced whereas the others are delayed or inhibited under different ambient conditions. Under ex vitro conditions, plants of the same genotypes can have dissimilar growth habits when subject to different conditions $^{[3]}$. Terrestrial plants are absolutely dependent on light to provide the energy they need for growth and reproduction through photosynthesis. Light quality (and/or periodicity) is one of the most important environmental signals that might modify the regeneration response in tissue culture ${ }^{[4]}$. It is therefore crucial for a plant to maximize its photosynthetic capability by responding to the light environment around it.

In tomato, light may influence the regeneration response by two ways, viz;

1. Via mother plant: the regeneration response of tomato explants could depend on the quality and quantity of light used in raising the mother plant ${ }^{[5]}$. Generally, the explants obtained from etiolated seedlings fail to show good regeneration respons $\mathrm{e}^{[4]}$.

2. Via explant: light conditions imposed upon the explants during incubation can also affect explant response. Tomato explants cultured in white light show better regeneration than those grown in red or green light ${ }^{[6]}$. Pugliesi et al. ${ }^{[7]}$ reported that light is absolutely essential for regeneration of tomato shoots, as they found no regeneration in the absence of light.

A strong relationship between the original position of the explants in the seedling and light conditions during regeneration has also been reported $d^{[5]}$. For example, the regeneration response of the apical meristem was enhanced by frequent irradiation with red light, whereas the response of the basal nodes remained unaffected. However, the white light dependent regeneration ability of de-etiolated hypocotyl explant was not influenced by the original position of explants on the seedling ${ }^{[7]}$. The type of organogenic response also depends on the light. For example, Tyburski and Tretyn ${ }^{[8]}$ found that the etiolated explants formed roots in the presence of light despite being grown on a shoot-inducing medium, whereas the non-etiolated plants produced shoots only

Corresponding Author: Poonam Bhatia, Primary Industries Research Centre, School of Biological and Environmental Sciences, Central Queensland University, Rockhampton, QLD 4702, Australia

Fax: + 61749309255 E-mail: p.bhatia@cqu.edu.au 
under certain conditions. This root regeneration response from etiolated explants was stimulated by short, fiveminute daily pulses of red light.

Most studies on tomato regeneration have employed a $16 \mathrm{~h}$ photoperiod. Studies on the effects of diurnal variation in the length of exposure to light are lacking.

The current study was undertaken to determine the effect of light: dark cycles on shoot regeneration, number of shoots produced, shoot height and chlorophyll content of the regenerated shoots.

\section{MATERIALS AND METHODS}

Explant: Seeds of the Red Coat cultivar were obtained from Yates Vegetable Seeds Co. Ltd. (Milperra, NSW, Australia). Seeds were surface sterilized for $15 \mathrm{~min}$ with $1 \%(\mathrm{v} / \mathrm{v})$ sodium hypochlorite and rinsed with sterile water before being transferred to autoclavable transparent culture tubes $(25 \times 80 \mathrm{~mm})$ containing $5 \mathrm{~mL}$ MS basal medium which contained $0.8 \%$ agar (Sigma Chemical Company, St Louis, MO, USA). Cotyledons were excised from one-week-old seedlings and the whole cotyledons were inoculated onto regeneration medium (one explant per tube). Explants were placed with the abaxial (lower) surface touching the medium and the tubes were incubated in a controlled environment room (CER) maintained at $25 \pm 2^{\circ} \mathrm{C}$ with an incident light intensity of $38 \mu \mathrm{mol} \mathrm{m} \mathrm{m}^{-2} \mathrm{~s}^{-1}$. The light was provided by cool white fluorescent tubes (Sylvania Gro-Lux, Germany) and the light treatments of (I) $24 \mathrm{~h}$ light, (ii) $24 \mathrm{~h}$ dark and (iii) $16 \mathrm{~h}$ light and $8 \mathrm{~h}$ dark were compared using 45 replications per treatment. The standard condition of the CER was $16 \mathrm{~h}$ light and $8 \mathrm{~h}$ dark. Dark condition $(24 \mathrm{~h})$ was simulated by covering some of the shelves in the CER with non-airtight black poly sheets. For simulating $24 \mathrm{~h}$ light conditions, some of the shelves were covered with non-airtight poly sheet and lights on those shelves were switched on continuously.

Regeneration medium: The regeneration medium consisted of the MS basal medium which was supplemented with $15 \mu \mathrm{M}$ zeatin and 3\% sugar and solidified with $0.8 \%$ agar. The medium $\mathrm{pH}$ was adjusted to 5.8 using $1 \mathrm{M} \mathrm{NaOH}$ or $0.25 \mathrm{M} \mathrm{HCl}$ and mechanically dispensed ( $5 \mathrm{~mL}$ per tube) into transparent plastic culture tubes $(25 \times 80 \mathrm{~mm})$ prior to autoclaving at $1.05 \mathrm{~kg} \mathrm{~cm}^{-2}$ $(103.5 \mathrm{kPa})$ at $121^{\circ} \mathrm{C}$ for $15 \mathrm{~min}$. The medium was cooled to $40^{\circ} \mathrm{C}$ before tightening the lids to minimise condensation.
Observations: Observations were recorded after four weeks of inoculation. The number of explants showing organogenesis and callus formation was counted and the callus diameter, number of shoots per explant and shoot height was measured.

Experimental design and statistical analysis: For each treatment 45 culture tubes were used. Standard errors of the means and confidence intervals were used to compare shoot height, callus diameter and number of shoots. Graphs were prepared using Sigma Plot (SPSS Inc., USA).

Chlorophyll determination: The leaf extract was prepared using $80 \%$ acetone. The chlorophyll content was quantified by measuring the absorption at $\lambda 652 \mathrm{~nm}$ using a spectrophotometer. Five replications per treatment were used. The oldest three leaves (c.3 mm long) of the regenerated shoots were used to extract chlorophyll.

\section{RESULTS AND DISCUSSION}

Maximum shoot regeneration (60\%) occurred in the explants exposed to $16 \mathrm{~h}$ light and $8 \mathrm{~h}$ dark. The $24 \mathrm{~h}$ dark $(47 \%)$ and $24 \mathrm{~h}$ light $(40 \%)$ had similar regeneration responses which were much lower than that observed at $16 \mathrm{~h}$ light (Fig. 1). The $16 \mathrm{~h}$ light and $24 \mathrm{~h}$ dark treatments had similar numbers of shoots per explants (3.2-3.3), whereas the $24 \mathrm{~h}$ light treatment produced lower number of shoots per explant 2.7 (Fig. 2). The $24 \mathrm{~h}$ light treatment produced the tallest $(3 \mathrm{~mm}$ ) seedlings followed by $16 \mathrm{~h}$ light $(4.5 \mathrm{~mm})$ and $24 \mathrm{~h}$ dark $(3.9 \mathrm{~mm})$ (Fig. 3; Plate 1a). The callus response was only slightly affected by the light, as it ranged between $62-67 \%$ amongst the three treatments (Fig. 4). However, the size of callus was highest (11.2 mm) in $24 \mathrm{~h}$ light followed by $16 \mathrm{~h}$ light $(7.9 \mathrm{~mm})$ and $24 \mathrm{~h}$ dark $4.3 \mathrm{~mm}$ (Fig. 5). The chlorophyll content was highest in the shoots exposed to $16 \mathrm{~h}$ light $\left(77 \mathrm{mg} \mathrm{L}^{-1}\right)$ followed by $24 \mathrm{~h}$ light (54 $\left.\mathrm{mg} \mathrm{L}^{-1}\right)$ and $24 \operatorname{dark}\left(11 \mathrm{mg} \mathrm{L}^{-1}\right)$ and the difference between the $16 \mathrm{~h}$ and $24 \mathrm{~h}$ light treatments was not marked compared to that with $24 \mathrm{~h}$ dark treatment (Fig. 6). The shoots that were regenerated under dark were chlorotic (Plate 1b) and they developed chlorophyll only after they were transferred to $16 \mathrm{~h}$ photoperiod.

Results of this study demonstrate that tomato can be regenerated in the absence of light. These findings contradict those of Tyburski and Tretyn ${ }^{[8]}$ who found that light was essential for shoot regeneration from vegetative explants obtained from either green or etiolated seedlings of tomato. Pugliesi et al. ${ }^{[7]}$ also demonstrated that no 


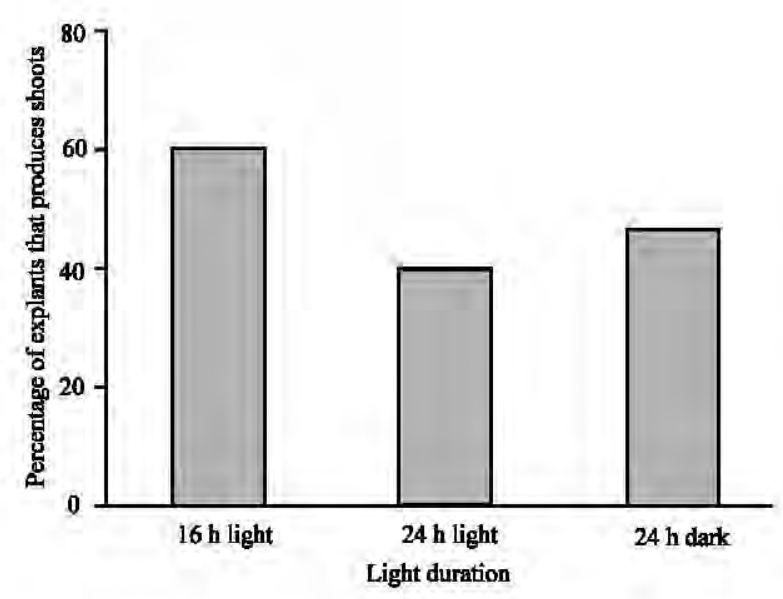

Fig. 1: Effect of light duration on the percentage of cotyledonal explant of $\mathrm{CV}$. Red Coat that produced shoot in four weeks time $(n=45)$

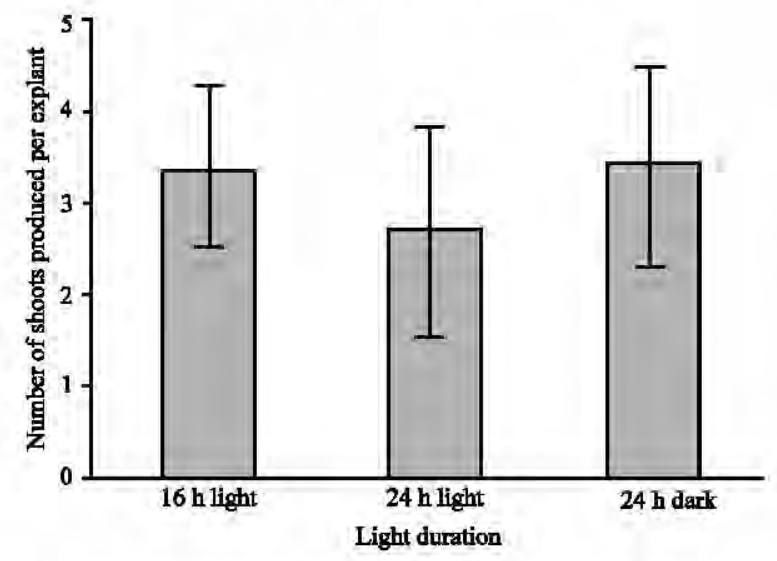

Fig. 2: Effect of light duration on the number of shoots produced per cotyledonary explant of $\mathrm{CV}$. Red Coat in four weeks time $(\mathrm{n}=18-27)$ shoots produced per explant

regeneration is possible in the absence of light. However, Gresshoff and Doy ${ }^{[9]}$ reported that callus differentiation in tomato anthers was independent of light conditions, if the medium was supplemented with suitable PGRs, but the callus development into plantlets was only possible if light was present. Similarly, Behki and Lesley ${ }^{[10]}$ found that morphogenic differentiation of callus was dependent on light. Consistent with these findings, Chlyah and Taarji ${ }^{[1]]}$ could successfully regenerate tomato shoots from anthers in the absence of light. Contradictory results exist for the effect of light on regeneration response of other crops. For example, Compton ${ }^{[12]}$ demonstrated that optimal shoot regeneration in watermelon can be obtained by germinating embryos in dark prior to dissecting

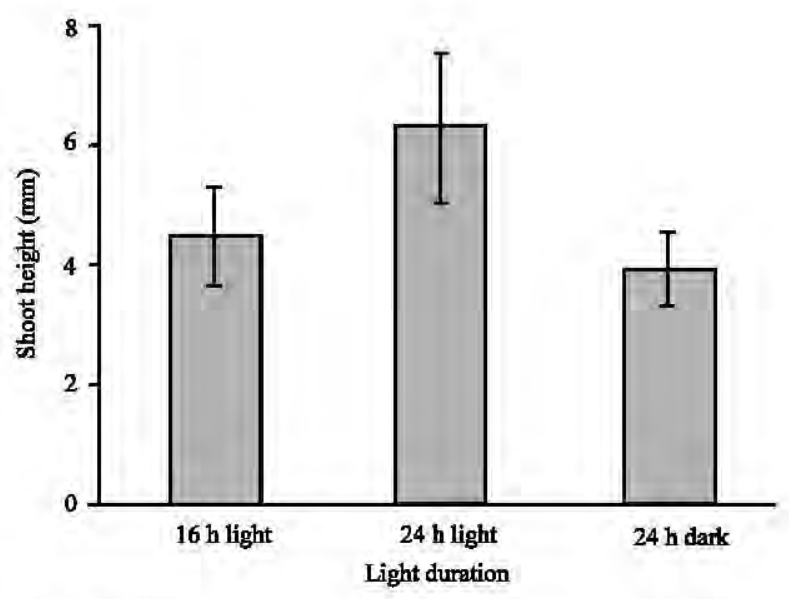

Fig. 3: Effect of light duration on the height of regenerated shoots developed from cotyledonary explant of Cv. Red Coat in four weeks time $(n=18-$ 27)

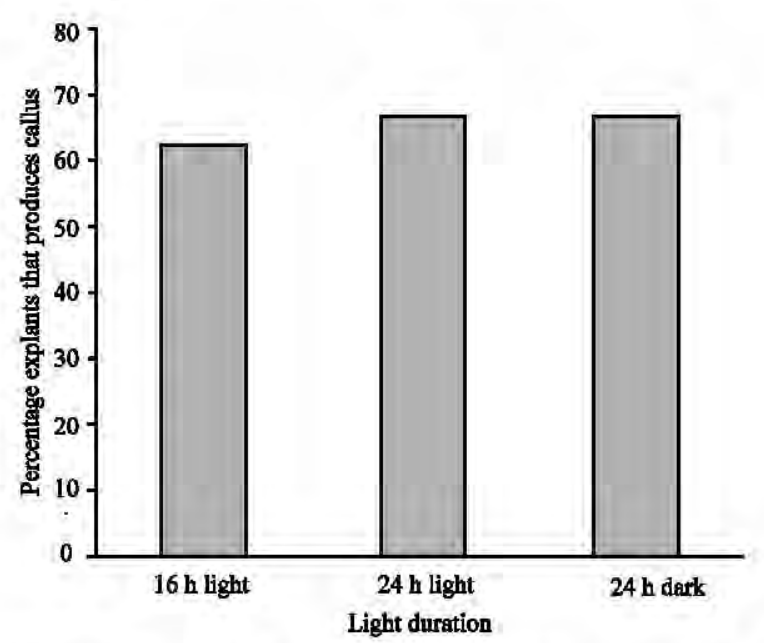

Fig. 4: Effect of light duration on the percentage of cotyledonal explant of $\mathrm{Cv}$. Red Coat that produced callus in four weeks time $(n=45)$

cotyledonary explants for inoculation. In contrast, Marcotrigiano et $a l^{[13]}$ obtained maximum regeneration in light from the leaf explants of two cultivars of cranberry (Vaccinium macrocarpon). In summary the effect of light on regeneration is species specific. The number of shoots produced per explant was found to be similar for all treatments. The possible explanation for this could be the acquisition of competence for regeneration.

Tomato cells seem to have a high regenerative capacity and do not require external stimuli such as light for shoot regeneration as suggested by Lercari et al.$^{[5]}$. The lower shoot number in $24 \mathrm{~h}$ light than in $16 \mathrm{~h}$ could be due to the fact that continuous exposure to light leads to simultaneous action of several photoreceptors for several 


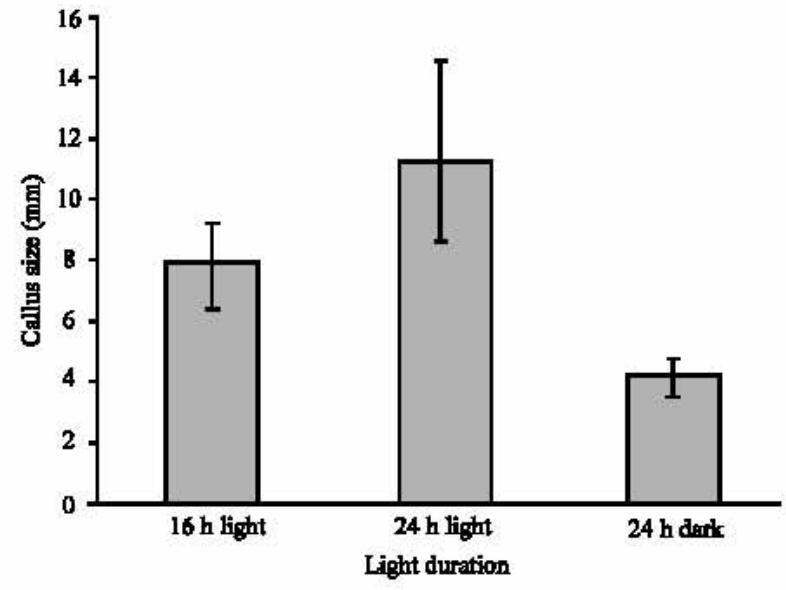

Fig. 5: Effect of light duration on diameter of the callus developed from cotyledonary explants of $\mathrm{Cv}$. Red Coat in four weeks time $(n=28-30)$

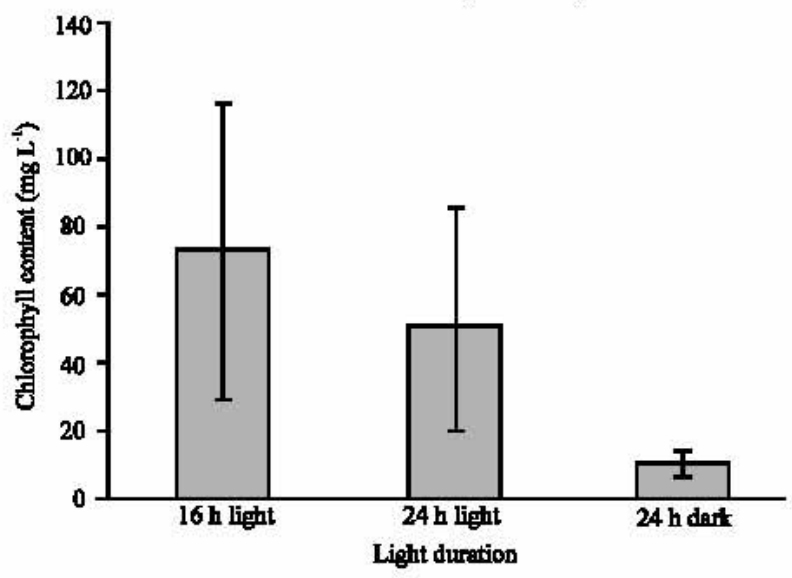

Fig. 6: Effect of light duration on chlorophyll contents of shoots developed from cotyledonary explants of Cv. Red Coat in four weeks time $(n=5)$ days in a detrimental way that renders the cells to be incompetent/ partially competent for shoot regeneration resulting in reduced number of shoots per explant.

Interestingly, in the current study, shoots that regenerated in the dark did not show the typical etiolated growth, which is characterised by elongated shoot and extended internodes. When a seedling breaks through the soil surface into a sunlit environment, elongation of the stem is inhibited and the emphasis of development shifts from straight growth to expanding photosynthetic capacity. Both the blue and red components of white light cause inhibition of stem elongation ${ }^{[14]}$. Regenerated shoots in the dark in this study exhibited non-etiolated growth. This behaviour could be explained through cytokinin-light interaction. This interaction also explains

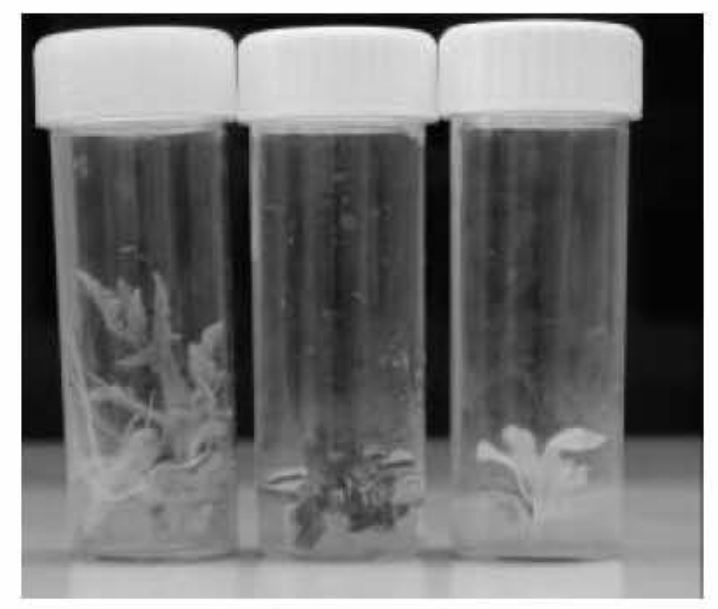

Plate 1a: Effect of light duration on shoot regeneration in tomato Cv. Red Coat (shoots regenerated in 24 $\mathrm{h}$ light, $16 \mathrm{~h}$ light and $24 \mathrm{~h}$ light dark conditions; left to right)

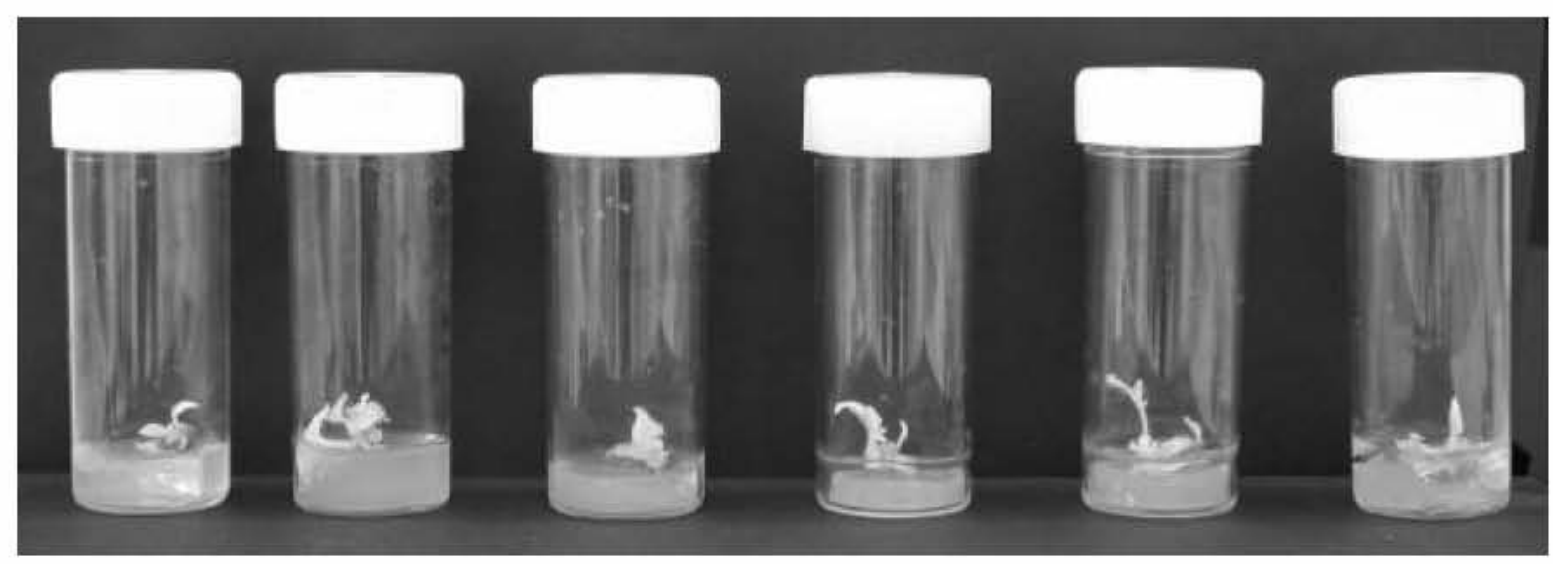

Plate 1b: Shoots regenerated in $24 \mathrm{~h}$ dark conditions showing very low chlorophyll content 
the occurrences of shoot regeneration in the absence of light in the current study. It is becoming increasingly convincing that PGRs control light-mediated changes. Light regulated processes can be mimicked by exogenous application of high concentrations of cytokinin to darkgrown seedlings ${ }^{[3]}$. Mutants containing elevated levels of cytokinin display aspects of de-etiolation even when grown in the $\operatorname{dark}^{[15]}$. It has been observed that 'AtpC which is a light regulated gene, is also regulated by cytokinins ${ }^{[16]}$. The reverse is also true: the arabidopsis ARR 4 response regulator, an early cytokinin response gene, is also induced in response to red light in a phyB dependent manner ${ }^{[17]}$. However, the exact mechanism of cytokinin promoting non-etiolation response in the dark is still not fully understood.

Very low chlorophyll concentration was observed in the dark- regenerated shoots. In line with the observation of the current experiment Tapingkae and Taji ${ }^{[18]}$ also reported reduction in the chlorophyll content of Zieria fraseria with increased light intensity. The light acts as the main regulator of the ultra structural organization of the plant photosynthetic apparatus ${ }^{[19]}$. Thus, in the absence of light proper chlorophyll development was severely hampered. Although cytokinins play a role in leaf greening, this activity is controlled by the two-component system, viz., cytokinin and light ${ }^{[20]}$ and cytokinin co-acting along with light signaling pathway ${ }^{[17]}$. Moreover, reduced chlorophyll content was observed in the shoots regenerated in $24 \mathrm{~h}$ light conditions and this probably due to photo inhibition. Photo inhibition is an inhibition of growth and in extreme cases death of cell and tissue. Research into the mechanisms of photo inhibition is a large field of research in photosynthesis and controversy among the researchers regarding the cause of photo inhibition. The role of UV light is amongst the most controversial topics in this field. The presence of UV light does have biochemically detectable effects, but photo inhibition probably does not absolutely require UV (Dr. Curtis Hoganson - Personal communication). In the current experiment, the role of sucrose in inhibiting the cholorophyll development can be rule out as the sucrose concentration was same in all the light treatments.

In summary, shoot regeneration process in tomato is independent of light; and the shoots regenerated in the dark show no etiolation characteristics except that they lacked chlorophyll content, which was readily developed following exposure to $16 \mathrm{~h}$ light.

\section{REFERENCES}

1. Bhatia, P., N. Ashwath, T. Senaratna and D. Midmore, 2004. Tissue culture studies of tomato (Lycopersicon esculentum) Review. Plant Cell Tis. Organ Cult., 78: 1-21.
2. Ohki, S., C. Bigot and J. Mousseau, 1978. Analysis of shoot-forming capacity in vitro in two lines of tomato (Lycopersicon esculentum Mill.) and their hybrids. Plant Cell Physiol., 19: 27-42.

3. Halliday, K.J. and C. Fankhauser, 2003. Phytochromehormonal signalling networks. New Phytologist, 157: 449-463.

4. Bertram, L. and B. Lercari, 2000. Phytochrome A and phytochrome B1 control the acquisition of competence for shoot regeneration in tomato hypocotyl. Plant Cell Reports, 19: 604-609.

5. Lercari, B., A. Manetti and L. Bertram, 2002. Temporal and spatial pattern of light-dependent acquisition of competence for shoot formation in tomato hypocotyl: Light pulse conditions. Advances in Hort. Sci., 16: 17-24.

6. Schutze, R. and G. Wieczorrek, 1987. Plant regeneration in plated callus primary suspensions of the cultivated tomato Lycopersicon esculentum Mill. $\mathrm{Cv}$. 'Nadja' in dependence on phytohormone content. Archiv fur Zuchtungsforschung, 17: 185-190.

7. Pugliesi, C., G. Cionini, L. Bertram and B. Lercari, 1999. A histological study of light-dependent shoot regeneration in hypocotyl explants of tomato cultured in vitro. Advances in Hort. Sci., 13: 168-172.

8. Tyburski, J. and A. Tretyn, 1999. Organogenetic response of photomorphogenic mutants of tomato. J. Plant Physiol., 155: 568-575.

9. Gresshoff, P.M. and C.H. Doy, 1972. Development and differentiation of haploid Lycopersicon esculentum (tomato). Planta, 107: 161-170.

10. Behki, R.M. and S.M. Lesley, 1980. Shoot regeneration from leaf callus of Lycopersicon esculentum. Zeitschrift fur Pflanzenphysiologie, 98: 83-87.

11. Chlyah, A. and H. Taarji, 1984. Androgenesis in Tomato, In F.J. Novak, L. Havel and J. Dolezel (Eds.), Plant Tissue and Cell Culture Application to Crop Improvement. Czechoslovak Academy of Sciences, Prague, Czechoslovakia, pp: 241-242.

12. Compton, M.E., 1999. Dark pretreatment improves adventitious shoot organogenesis from cotyledons of diploid watermelon. Plant Cell Tis. Organ Cult., 58: 185-188.

13. Marcotrigiano, M., S.P. McGlew, G. H ackett and B. Chawla, 1996. Shoot regeneration from tissuecultured leaves of the American cranberry (Vaccinium macrocarpon). Plant Cell Tis. Organ Cult., 44: 195-199.

14. Meijer, G., 1968. Rapid growth inhibition of gherkin hypocotyls in blue light. Acta Botanica Neerlandica, 17: 9-14. 
15. Chin-Atkins, A., S. Craig, C. Hocart, D. Dennis and A. Chaudhury, 1996. Increased endogenous cytokinin in the Arabidopsis ampl mutant corresponds with de-etiolation responses. Planta, 198: 549-556.

16. Kusnetsov, V., M. Landsberger, J. Meurer and R. Oelmuller, 1999. The assembly of the CAAT-box binding complex at a photosynthesis gene promoter is regulated by light, cytokinin and the stage of the plastids. J. Biol. Chem., 274: 36009-36014.

17. Sweere, U., K. Eichenberg, J. Lohrmann, V. Mira-Rodado, I. Baurle, J. Kudla, F. Nagy, E. Schafer and K. Harter, 2001. Interaction of the response regulator ARR4 with phytochrome $\mathrm{B}$ in modulating red light signaling. Science, 294: 1108-1111.
18. Tapingkae, T. and A. Taji, 2000. Light quality and quantity: their effects on in vitro growth and development of two Australian plant species. Acta Hort., 541: 281-288.

19. Silaeva, A.M., 1978. Role of the Light Factor in Organization of Chloroplast Structure. Fiziologiya I Biokhimiya Kul'Turnykh Rastenii, 10: 563-572.

20. Schmulling, T., 2002. New insights into the functions of cytokinins in plant development. J. Plant Growth Regulation, 21:40-49. 